\title{
Evaluation of pneumatic inclined deck separator for high-ash Indian coals
}

\author{
Nikhil Gupta ${ }^{1}$
}

Received: 17 October 2015/Revised: 6 January 2016/Accepted: 11 March 2016/Published online: 8 June 2016

(C) The Author(s) 2016. This article is published with open access at Springerlink.com

\begin{abstract}
Application of pneumatic separators in coal beneficiation is increasing rapidly over the last decade primarily due to their low capital and operating costs, and waste handling problems associated with traditional wet processing methods. Large amount of shale/rock that is extracted in coal production can be removed prior to transportation at the mine face by using this methodology. Due to the limited washing facilities in India, most of the thermal power plants burn raw coal from run-of-mine (ROM) to generate electricity. This practice causes poor utilization efficiency, high operating and maintenance costs, and high emission rates for the power plants. One potential method that can be utilized is the air-fluidized inclined vibrating deck technology. The technology was demonstrated on a pilot-scale at different coal washeries in India at a feed rate of 5-ton per hour. The pilot-scale evaluation showed that $20 \%-25 \%$ high-ash incombustible material can be eliminated from ROM feed with only minor losses in energy content $(<10 \%)$ from respective ROM coal. Furthermore, a feasibility analysis showed significant economic gains in terms of transportation cost, improving power-plant efficiency, and reducing emissions rates by using the technology.
\end{abstract}

Keywords Coal deshaling $\cdot$ Pneumatic separation $\cdot$ Inclined deck $\cdot$ Vibrating table $\cdot$ Fluidization

\section{Introduction}

In 2014, the United Nations' Intergovernmental Panel on Climate Change (IPCC) issued the Fifth Assessment Reports (AR5). The report from the Working Group I (The Physical Sciences Base) stated that the warming trend which began since the mid-twentieth century is real and it is "very likely" due to the increase in the atmospheric concentrations of the anthropogenic greenhouse gases (GHGs) such as carbon dioxide $\left(\mathrm{CO}_{2}\right)$, methane $\left(\mathrm{CH}_{4}\right)$, nitrous oxide $\left(\mathrm{N}_{2} \mathrm{O}\right)$ and others. Of these, $\mathrm{CO}_{2}$ accounts for $65 \%$ of the greenhouse gases generated largely from burning fossil fuels and other industrial applications. The

Nikhil Gupta

nikhilng@vt.edu

1 Postdoctoral Research Associate, Department of Mining and Minerals Engineering, Virginia Tech, Blacksburg, VA 24061, USA atmospheric $\mathrm{CO}_{2}$ concentration of $390 \mathrm{ppm}$ in 2014 far exceeded the range (180-300 ppm) observed during the last 650,000 years, and the use of fossil fuels was its major source. The report clearly suggests that there is a dire need to reduce the GHG emissions to the level that can be absorbed by the Earth's system (IPCC 2013).

India is the third largest GHGs emitter in the world, behind China and the United States (World Bank 2015), and its energy supply is largely dependent on coal. As one of the fastest growing economies of the world, its coal consumption is expected to increase rapidly, along with all of the environmental concerns associated with burning coal. An attractive first step toward reducing the $\mathrm{CO}_{2}$ emissions from the coal-fired power plants in India would be to increase the availability of beneficiated coals by using appropriate separation technologies. It has been shown that use of beneficiated coals can increase thermal efficiencies by $2 \%-3 \%$ on existing PC boilers, possibly as much as $4 \%-5 \%$, and can thereby reduce $\mathrm{CO}_{2}$ emissions up to $15 \%$ (Zamuda and Sharpe 2007). If the low-ash coals are 
used as feedstocks for advanced clean coal technologies, such as Integrated Gasification Combined Cycle (IGCC) or supercritical Pulverized Coal Technology (PCT), the thermal efficiencies can become as high as $45 \%$, which will further reduce the GHG emissions. The use of beneficiated coals will also have many other positive benefits. For example, beneficiated coal can increase in the plant utilization factor (PUF) by $13 \%$, minimize fouling and slagging problems, reduce fugitive dusts, and decrease in the amounts of unburned carbon in fly ash (Couch 2002). More importantly, shipping beneficiated coals will increase railway capacities on an equivalent heat basis, which will be of paramount importance in India.

In the fiscal year 2013-2014, India consumed 739.7 million metric tons (MMT) of coal, out of which $71 \%$ was used for thermal power plants (MOP 2015). Of this, domestic supply could only fulfill $76 \%$ of the country's demand. Unfortunately, the coal industry in India has been slower than in other countries in embracing coal beneficiation as part of their normal operating practice. At present, domestic coal accounted only less than $20 \%$ was beneficiated, out of which $97 \%$ operations involve water based separation methods (MOC 2015). The reasons for minimal beneficiation includes the difficulty in cleaning Indian coals, the high capital and operating costs associated with the conventional wet-beneficiation processes, and the lack of capital. Ash-forming minerals are finely dispersed in the Indian coals throughout the carbonaceous matrix, making them difficult to be removed using conventional physical separation methods. Further, water used in traditional water-based beneficiation plants is a scarce resource, especially in the coal mining areas. As per an estimate, the water table in India is shrinking rapidly (Tiwari et al. 2009), which makes alternative methods such as dry coal cleaning extremely beneficial.

Preliminary studies conducted for dry coal beneficiation suggest that these methods can be an effective technoeconomical tool for the Indian coal industry (Honaker 2007). Significant amount of rock are extracted in order to recover the coal; reportedly resulting in $60 \%-70 \%$ of the raw material as waste. The haulage, processing, and combustion of rock represent a significant loss of limited available resources and create negative environmental impact (Biswal et al. 2002). Removing unwanted rock from run-of-mine (ROM) coal is referred to as deshaling, which normally involves separation of high-density rock from raw coal in a density-based process. In contrast to traditional coal preparation plants, the separation relative density $(R D)$ for deshaling is higher with a typical target of $R D=2.0$ or greater (Honaker et al. 2008).

Several dry coal separation technologies, such as, AllAir ${ }^{\circledR}$ Jig (allmineral GmbH), Air Dense Medium Fluidizied Bed (ADFMB), Tirbo-electrostatic Separators, Rare Earth
Magnetic Separators (REMS), and X-ray Sorting technologies, were proven effective in terms of separation to achieve low-ash products for coarse to mid-size fractions (Dwari and Rao 2008; Zhao et al. 2014). In previous years, All-Air ${ }^{\circledR}$ Jig (ISR 2005; Gouri et al. 2007) and ADFMB (Sahu et al. 2005) have been tested for coarse Indian coal feedstock, and the data showed moderate recoveries to achieve low-ash product. The reason for lower recoveries could be due the poor formation of Indian coals, where particles are not liberated well at the coarse size fraction. However, these technologies can be applicable for the purpose of deshaling to remove high ash rock from ROM coals as pre-beneficiation method. Using dry coal separators for pre-beneficiation can provide significant economic savings. In general, the most cost-effective approach is to install the dry deshaling unit as near as possible to the mine extraction face to reduce transportation and maintenance costs (Honaker et al. 2006).

One such emerging technology that has been proven very effective in major coal producing countries is the airfluidized inclined vibrating deck technology.

The method utilizes integrated effect of vibration force (maceration) and continuous air flow for segregation of particles according to their densities (refer Fig. 1). The present communication highlights pilot-scale evaluation of the vibrating air-deck technology tested at the different coal beneficiation plants in India for the specific purpose of deshaling. In addition, a feasibility study was conducted using a cost-benefit model described by Gupta et al. (2014) to demonstrate economic gains by using this technology.

\section{Testing procedure}

\subsection{Inclined deck separator technology}

The dry coal vibrating air-table deshaling technique utilizes density separation in autogenous medium using a shaking table concentrator. The air table generates a helical motion with air stratification (as illustrated in Fig. 2a) and generates multiple products of clean coal, middlings, and reject (Dwari and Rao 2007). The separating compartment comprises a table with a perforated deck; vibrating motors, dust collecting air-chamber, and table support/adjusting pulleys. The main centrifugal fan provides continuous flow of air that passes upward through the perforated deck at a sufficient rate to transport and fluidize the particles. Diagonal riffles on the vibrating deck move material towards a back plate. The deck width is reduced from the feed to refuse discharge end. Furthermore, two dust collection systems are installed to clean the recycled air, and to remove the coal dust from air being emitted into the atmosphere. 

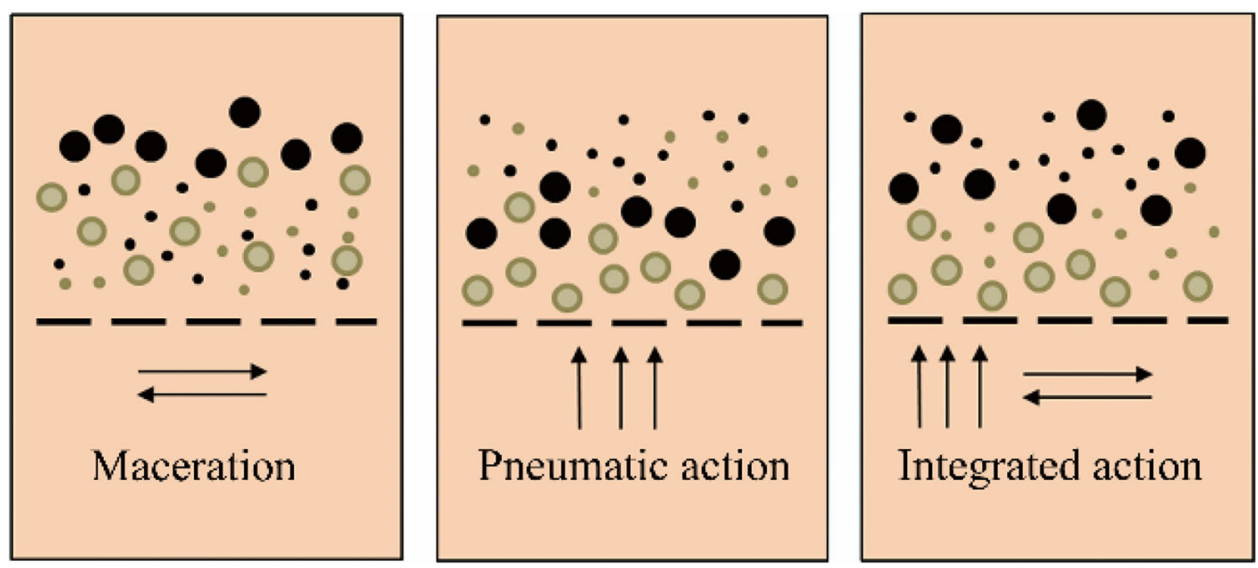

Fig. 1 Schematic shows operating principle of inclined deck separator

(a)

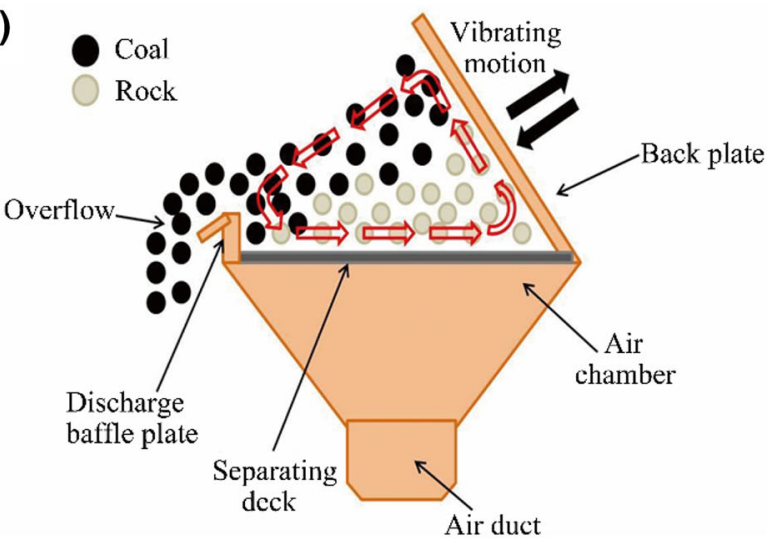

(b)

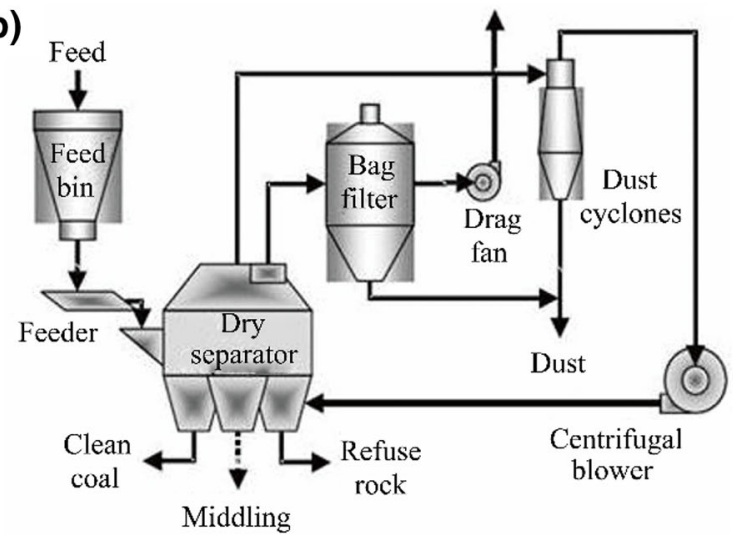

Fig. 2 Schematics showing a working mechanism and $\mathbf{b}$ process flow diagram of vibrating air-table separators (after Gupta 2011)

The bulk of air used for fluidization is recycled back to the table $(90 \%)$ after being cleaned in a dust cyclone, while the rest $10 \%$ is emitted to the atmosphere after passing through a bag-house filter. The bag-house filter creates a negative pressure within the unit to trap all the dust generated by the process. A simplified process flowsheet is shown in Fig. $2 b$.
The feed bin vibrating feeder controls the feed rate to the separating table. As ROM coal is introduced to the separation zone, a thick bed of particles forms on the vibrating deck. The heavier or high-density particles transport through the bed, comes in contact with the deck, and move toward the back plate under the influence of the inertia force generated due to deck vibration. Particles when strike the back plate, they move inward and upward in the direction of the discharge side of the table. During operation, lighter or low-density particles float on the top of the bed as they are pushed up at the back plate, and flow to the discharge point. As such, the lighter particles create an upper layer that is collected alongside the deck length. Particles of sufficient high-density sinks through the autogenous medium formed due to the bed of particles fluidized due to constant air-flow, and report back to the deck surface. These high-density particles are then forced by both vibration and the continuous influx of new feed material to transport in a helical pattern at the narrow end of the deck where the final reject is collected. Two or three products are collected from the front side of the table. For pilot-scale evaluation, a 5-tph air-table deshaling unit utilizing a $1 \mathrm{~m}^{2}$ air table was tested at three different test sites in India. An immanent advantage of this technology is that it is a dry separator, which delivers a dry product without incurring any dewatering costs.

\subsection{Test sites description}

Pilot-scale testing sessions were conducted at the two private coal groups, Aryan Energy Pvt. Ltd. in Talcher and Bhushan Power \& Steel Ltd. in Jharsuguda, and at the Kargali Washery, Coal India Ltd. located in Bokaro, Jharkhand. The coals procured for evaluation at the Aryan Energy site were from two different seams, Balaram and Hingula, of the Mahanadi Coalfields. These coals have a 
relatively high feed ash and are generally difficult to wash due to high proportions of near-gravity material (NGM). Similarly, the coals received for assessment at the Bhushan Power \& Steel complex were mixed of Mahanadi and IBValley coalfields. The facility process coals from multiple sources. At the Kargali Washery, the ROM coal received for evaluation was from three different coal seams of the Karanpura coalfields. These coals are also contains high ash with a high percentage of NGMs. For the coal samples evaluated, average feed ash contents were reported $48.7 \%$, $54.9 \%$, and $54.6 \%$ on a dry-basis $(\mathrm{db})$ for the Aryan, Bhushan, and Kargali facility, respectively. Typical surface moisture is ranged as low as 3\%-7\% and as high as $13 \%-$ $17 \%$ during rainy season.

\section{Results and discussion}

The pilot-scale studies in India were conducted in a statistical designed experimental set-up for the three test sites. The detail description of experimental design has been described elsewhere (Gupta et al. 2016). The major operating parameters were adjusted in each pilot test run. Once the unit achieved steady state, and the samples for clean coal, middlings, and reject were taken in three increments. The operating variables evaluated during the pilot-scale testing in India were the table slope (length-wise angle), the table oscillating frequency, and the main fan motor speed (Honaker and Luttrell 2007; Gupta et al. 2012). Honaker et al. (2008) parametric studies on the pilot-scale unit for the U.S. coals and indicated that the table crosswise angle had minimal influence on the separation performance, and therefore, can be held constant.

Table 1 exhibits a comprehensive analysis of the products obtained from the pilot tests conducted at the three test sites. This analysis includes product mass (wt $\%$ ), reject mass (wt $\%$ ), reject ash content (wt $\%$ ), the energy loss $(\mathrm{kcal} / \mathrm{kg} \%)$ relative to the feed, organic matter recovery (wt\%), and mineral matter rejection (wt\%). Mathematically, percent energy loss can be calculated from the threeproduct formula utilizing the energy contents $(\mathrm{kcal} / \mathrm{kg})$ of feed, clean coal, and the reject streams (Wills and NapierMunn 2006) from the following equation:

$\%\left(\frac{\mathrm{kcal}}{\mathrm{kg}}\right)$ Loss $=\%$ Reject mass $\times \frac{\left(\frac{\mathrm{kcal}}{\mathrm{kg}}\right) \text { of reject }}{\left(\frac{\mathrm{kcal}}{\mathrm{kg}}\right) \text { of feed }}$

In addition, the analysis includes organic matter recovery of product (clean coal middling) stream obtained in each test. This indicator represents amount of "organics" recovered in the product relative to the feed, which can be estimated from the mineral matter (inorganic) content of each product. Similarly, mineral matter rejection is represents the amount of inorganics in reject stream relative to feed.

The testing sessions at the Aryan Energy, Bhushan Power \& Steel Complex, and Kargali Washery sites successfully demonstrated that the dry coal inclined deck deshaling technology was capable of removing high-ash impurities with modest energy losses from the raw coal presently being processed by these coal groups. From the analysis, on an average $18 \%-22 \%$ of the waste (high-ash rock) material can be removed from the ROM coals with minimal loss (9.5-13.4 kcal/kg, \%) of energy content from feed to the reject stream. In other words, 1 in every 4-5 rail wagons (full-load) can be eliminated from ROM coal prior shipping with only a minor reduction in heat content by using the low-cost dry deshaling technology.

For Aryan and Bhushan coal samples, the vibrating airtable technology was able to achieve organic matter recovery on an average $87.8 \%-90 \%$ of all tests, while the average mineral matter rejections were about $24 \%$ only. In some tests, higher rejections were reported (e.g. test 11 for Aryan) but at the expense of significant loss in heat content of coal in reject. The low mineral matter rejection data for Aryan and Bhushan suggest that the ROM coal carry significant amount of middlings material than the pure highash rock material. As such, further liberation of particles in these samples is necessary for better separation of ash from coal.

However, significant improvements were seen for the case of Kargali coal samples using the deshaling technology. In most of the tests, more than $20 \%$ of the ROM material of ash content $80 \%$ was rejected with $<10 \%$ loss in heat content of coal. The separation was much better as evident from high organic matter recoveries in most test trials. For the operating conditions in test 1, the organic recovery was recorded $94.1 \%$ with the highest mineral matter rejection of $41.6 \%$. The results suggest that the Kargali coal sample carry large proportion of pure rock material in ROM coal, and would be a better candidate for deshaling.

Therefore, the pre-combustion removal of these high-ash impurities increased coal heating value and reduced ash disposal and coal transportation requirements without introducing new issues associated with traditional wet coal processing systems (such as, slurry disposal, water pollution, etc.). These analyses suggest that overall transportation costs may be reduced by up to $30 \%$ when compared on an equivalent energy content basis. This value is significant when one considers the fact that many of the railing distances can exceed $1200 \mathrm{~km}$ over rail lines in India that are typically overloaded. Recently, as per the Indian Ministry of Environment \& Forest, from June 2016 it will be mandatory for producers to supply coal not more than $34 \%$ ash content, 
Table 1 Results from pilot-scale tests for the three coal production facilities

\begin{tabular}{|c|c|c|c|c|c|c|c|}
\hline Location & Test no. & $\begin{array}{l}\text { Product mass } \\
\text { (Clean Midd.) } \\
\text { (wt\%) }\end{array}$ & $\begin{array}{l}\text { Reject } \\
\text { mass } \\
(\text { wt } \%)\end{array}$ & $\begin{array}{l}\text { Reject ash } \\
(\mathrm{wt} \%, \mathrm{db})\end{array}$ & $\begin{array}{l}\text { Energy } \\
\text { loss } \\
(\mathrm{kcal} / \mathrm{kg}, \%)\end{array}$ & $\begin{array}{l}\text { Organic } \\
\text { matter } \\
\text { recovery (wt } \%)\end{array}$ & $\begin{array}{l}\text { Mineral } \\
\text { matter rejection } \\
(\mathrm{wt} \%)\end{array}$ \\
\hline \multirow{14}{*}{$\begin{array}{l}\text { Aryan energy (Avg. feed } \\
\text { ash, } 48.7 \%, \mathrm{db})\end{array}$} & 1 & 85.2 & 14.8 & 67.7 & 9.0 & 92.2 & 21.2 \\
\hline & 2 & 82.3 & 17.7 & 60.9 & 13.2 & 87.8 & 22.9 \\
\hline & 3 & 75.6 & 24.4 & 60.4 & 18.9 & 82.3 & 30.2 \\
\hline & 4 & 85.0 & 15.0 & 58.9 & 11.6 & 89.1 & 18.7 \\
\hline & 5 & 79.6 & 20.4 & 64.1 & 14.2 & 87.1 & 26.9 \\
\hline & 6 & 89.5 & 10.5 & 64.6 & 7.3 & 93.4 & 13.7 \\
\hline & 7 & 88.1 & 11.9 & 61.6 & 8.5 & 92.2 & 15.9 \\
\hline & 8 & 93.2 & 6.8 & 62.2 & 4.8 & 95.6 & 9.1 \\
\hline & 9 & 76.1 & 23.9 & 61.5 & 17.7 & 83.6 & 30.7 \\
\hline & 10 & 80.0 & 20.0 & 63.1 & 13.4 & 87.9 & 28.1 \\
\hline & 11 & 65.8 & 34.2 & 63.4 & 24.8 & 77.2 & 43.6 \\
\hline & 12 & 79.5 & 20.5 & 66.3 & 13.3 & 88.2 & 28.2 \\
\hline & 13 & 76.9 & 23.1 & 66.8 & 14.7 & 87.1 & 32.4 \\
\hline & Avg. & 81.3 & 18.7 & 63.2 & 13.4 & 87.8 & 24.8 \\
\hline \multirow{14}{*}{$\begin{array}{l}\text { Bhushan complex } \\
\text { (Avg. feed ash, } 54.9 \% \text {, db) }\end{array}$} & 1 & 84.1 & 15.9 & 72.6 & 10.0 & 91.6 & 20.4 \\
\hline & 2 & 85.5 & 14.5 & 72.6 & 9.0 & 92.4 & 19.0 \\
\hline & 3 & 86.4 & 13.6 & 70.7 & 8.4 & 92.9 & 18.3 \\
\hline & 4 & 81.7 & 18.3 & 70.2 & 11.8 & 89.8 & 23.8 \\
\hline & 5 & 83.4 & 16.6 & 69.2 & 11.1 & 90.2 & 21.2 \\
\hline & 6 & 84.1 & 15.9 & 73.4 & 9.6 & 92.1 & 20.8 \\
\hline & 7 & 73.5 & 26.5 & 71.4 & 18.7 & 83.5 & 31.9 \\
\hline & 8 & 77.8 & 22.2 & 73.0 & 14.2 & 88.0 & 28.1 \\
\hline & 9 & 80.9 & 19.1 & 70.2 & 11.8 & 89.9 & 25.9 \\
\hline & 10 & 86.6 & 13.4 & 77.4 & 6.3 & 95.3 & 19.9 \\
\hline & 11 & 79.4 & 20.6 & 70.5 & 14.2 & 87.5 & 25.4 \\
\hline & 12 & 73.5 & 26.5 & 66.4 & 11.4 & 82.4 & 32.7 \\
\hline & 13 & 84.0 & 16.0 & 64.0 & 12.2 & 88.7 & 19.5 \\
\hline & Avg. & 81.6 & 18.4 & 70.9 & 11.6 & 90.0 & 23.8 \\
\hline \multirow{14}{*}{$\begin{array}{l}\text { Kargali washery } \\
\text { (Avg. feed ash, } 54.6 \% \text {, db) }\end{array}$} & 1 & 72.2 & 27.8 & 83.4 & 10.4 & 94.1 & 41.6 \\
\hline & 2 & 83.8 & 16.2 & 79.0 & 6.6 & 95.4 & 26.2 \\
\hline & 3 & 72.8 & 27.2 & 77.9 & 14.1 & 89.4 & 36.9 \\
\hline & 4 & 79.3 & 20.7 & 85.9 & 7.4 & 96.6 & 29.3 \\
\hline & 5 & 83.8 & 16.2 & 85.0 & 5.6 & 97.2 & 24.3 \\
\hline & 6 & 74.9 & 25.1 & 71.1 & 14.3 & 88.0 & 36.2 \\
\hline & 7 & 74.9 & 25.1 & 82.9 & 10.2 & 93.9 & 35.9 \\
\hline & 8 & 83.4 & 16.6 & 81.6 & 6.1 & 96.2 & 27.3 \\
\hline & 9 & 68.5 & 31.5 & 74.5 & 18.7 & 84.9 & 40.6 \\
\hline & 10 & 87.4 & 12.6 & 83.1 & 4.8 & 97.2 & 18.9 \\
\hline & 11 & 79.9 & 20.1 & 78.8 & 9.0 & 93.7 & 30.1 \\
\hline & 12 & 78.8 & 21.2 & 76.6 & 10.5 & 92.0 & 30.6 \\
\hline & 13 & 75.3 & 24.7 & 79.3 & 11.2 & 92.2 & 36.3 \\
\hline & Avg. & 78.1 & 21.9 & 80.0 & 9.5 & 93.5 & 32.1 \\
\hline
\end{tabular}

if transported to more than $500 \mathrm{~km}$ or in environmentally sensitive areas. As such, implementing low-cost vibrating air-table separators for deshaling purpose will be highly beneficial to the ever-growing Indian coal industry.

\subsection{Economic and efficiency analysis}

Using the pilot-scale test results for each site, a feasibility analysis was conducted to demonstrate impact the dry 
deshaling separation technology on power generation market. For the purpose, cost-benefit model developed by Gupta et al. (2014) was utilized. The model is specifically designed for the Indian coal market from a coal-fired power industry perspective. This model includes variable cost factors, such as, transportation cost (equivalent energy content) as a function of distance, ash and moisture handling cost, and other miscellaneous costs. For analyses, these factors were kept constant, that is, the transportation distance was assumed $200 \mathrm{~km}$, and the ash and moisture handling cost were kept at US $\$ 2.5 /$ ton of water and US \$ $1 /$ ton of ash, respectively. The target cost of thermal power plant boilers was kept constant to US $\phi 1.36 / \mathrm{kW}-\mathrm{h}$ identified by the researchers from extensive studies (Gupta et al. 2014). Finally, the moisture ash-free (maf) energy content of coal was assumed to $7500 \mathrm{kcal} / \mathrm{kg}$ based on preliminary analysis obtained for the three coal samples.

The aforementioned model evaluates thermal power plant efficiency with variation in ash content of the material to be burned. For the purpose, the model incorporates performance data obtained by Bhatt (2006), which examined various power plants in the range of 30-500 MW at a variable feed ash material ranging from $6 \%-75 \%$ ash, has been utilized. The maximum theoretical efficiency for the thermal power plants is $45 \%$. The study determined baseline efficiency to be $33.5 \%$ for the Indian power plants (Gupta et al. 2014) using the de-rating adjustment of $74.5 \%$ for $500 \mathrm{MW}$. In addition, various efficiency corrections factors, such as, boiler, auxiliary, and steam, were defined as a function of ash content in the model using the performance data reported in the literature (Bhatt 2006). Furthermore, the model also accounted efficiency losses due to moisture as $0.15 \%$ per $1 \%$ surface moisture in the power plant. For calculations, the moisture was assumed constant to $8 \%$.

Figure 3 demonstrate an example of feasibility study under the specified economic parameters for the results obtained for one of the pilot-tests conducted with Kargali coal sample. Rows ' $a-c$ ' indicated direct data obtained from the tests, while rows ' $d-e$ ' shows separation indicators. As described earlier, row ' $f$ ' represents de-rated power plant efficiency, which is further adjusted with correction factors (rows ' $f-k$ ') to calculated net thermal efficiency as shown in row ' $j$ '. Using this net efficiency and energy content of each stream (row ' $c$ '), actual energy content to be utilized in power plant was calculated that can be converted to gross worth ( $\$ /$ ton) of material (see row ' $o$ '). After adjusting with relevant cost factors (rows ' $p-s$ '), the net worth of each product was calculated (in row ' $t$ ').

As shown in the example, the true worth calculated on an equivalent energy content basis, the ROM feed is worth US $\$ 1.05 /$ ton, while after deshaling the value of material increased to US $\$ 5.36 /$ ton with organic matter recovery

\begin{tabular}{|c|c|c|c|c|c|}
\hline & COST ANALYSIS & & Product & Refuse & Feed \\
\hline$a$ & Mass & $\%$ dry & 72.22 & 27.78 & 100 \\
\hline$b$ & Ash & $\%$ dry & 45.0 & 83.4 & 55.6 \\
\hline \multirow[t]{2}{*}{ c } & Energy Content (Kcal/kg) & dry & 4282 & 1291 & 3451 \\
\hline & Energy loss in Reject & $\% \mathrm{Kcal} / \mathrm{kg}$ & & 10.4 & \\
\hline$d$ & Organic Matter Distribution & $\%$ & 94.1 & 5.9 & 100 \\
\hline$e$ & Mineral Matter Distribution & $\%$ & 58.4 & 41.6 & 100 \\
\hline$f$ & Baseline Efficiency & $\%$ & 33.54 & 33.54 & 33.54 \\
\hline$g$ & Moisture Correction & $\%$ & 98.8 & 98.8 & 98.8 \\
\hline$h$ & Boiler Correction & $\%$ & 93.31 & 73.84 & 89.18 \\
\hline$i$ & Auxillary Correction & $\%$ & 96.53 & 85.40 & 94.20 \\
\hline j & Steam Correction & $\%$ & 98.26 & 94.44 & 97.40 \\
\hline$k$ & Total Correction & $\%$ & 0.87 & 0.59 & 0.81 \\
\hline 1 & Net Efficiency & $\%$ & 29.32 & 19.73 & 27.11 \\
\hline$m$ & Gross Energy & $\mathrm{Kcal} / \mathrm{kg}$ & 1155 & 234 & 861 \\
\hline$n$ & Gross Energy & Kwh/ton & 1217 & 247 & 907 \\
\hline 0 & Gross Value & $\$ /$ ton & 16.56 & 3.36 & 12.34 \\
\hline$p$ & -Freight Cost & $\$ /$ ton & 10.08 & 10.08 & 10.08 \\
\hline$q$ & -Evaporation Cost & $\$ /$ ton & 0.2 & 0.2 & 0.2 \\
\hline$r$ & -Ash cost & $\$ /$ ton & 0.41 & 0.77 & 0.51 \\
\hline$s$ & -Miscellaneous & $\$ /$ ton & 0.5 & 0.5 & 0.5 \\
\hline \multirow[t]{2}{*}{$t$} & NET Value & $\$ /$ ton & 5.36 & $(8.19)$ & 1.05 \\
\hline & \multicolumn{5}{|l|}{ EMISSION ANALYSIS } \\
\hline$u$ & Gross Energy & $\mathrm{Kwh} / \mathrm{lb}$ & 0.61 & 0.12 & 0.45 \\
\hline$v$ & Emission/pound of coal & $\mathrm{lb}-\mathrm{CO}_{2} / \mathrm{lb}$ & 1.39 & 0.23 & 1.07 \\
\hline$w$ & Emission/unit energy & $\mathrm{Ib}-\mathrm{CO}_{2} / \mathrm{Kwh}$ & 2.29 & 1.84 & 2.35 \\
\hline$x$ & Net $\mathrm{CO}_{2}$ reduction & $\% \mathrm{lb}-\mathrm{CO}_{2} / \mathrm{Kwh}$ & & 2.92 & \\
\hline
\end{tabular}

Fig. 3 An example of feasibility analysis for one of the pilot test at Kargali Washaery

$94.1 \%$ and a minimal energy loss in reject stream $10.4 \%$ relative to feed. On the other side the reject stream after deshaling carry $83.4 \%$ ash that values (negative) -US $\$ 8.19 /$ ton. More notably, this stream is approximately $28 \%$ of the ROM coal. Similarly, the power plant utilization efficiency improved from $27.11 \%$ (for ROM) to $29.32 \%$ (for deshaled product), shown in row ' $l$ '. From these results, it is evident that the deshaling of ROM coal will be advantageous for the Indian coal industry.

Table 2 indicates economic gains and efficiency improvements using the feasibility model developed under the specified economic parameters for the pilot-scale unit. The analysis shows for the best operating conditions that include Test 13, Test 12, and Test 1 for Aryan, Bhushan and Kargali, respectively. As discussed above, the analysis showed net value increment (US \$/ton) of $2.39,1.81$, and 4.31 for the de-shaled coal relative to ROM coal for the three test sites. The proposed dry deshaling method demonstrated significant economic gain especially for the case of Kargali coal samples.

These economic gains can be very significant when evaluated on yearly basis. For example, every 500-tph deshaled coal can provide an additional gross revenue of $\$ 13$ million annually $(4.31 \$ /$ ton $\times 500$ ton $/ \mathrm{h} \times 6000 \mathrm{~h} /$ year $)$ 
Table 2 Economic, power plant efficiency, and emission analysis for the three test sites

\begin{tabular}{|c|c|c|c|c|c|c|}
\hline \multirow[t]{2}{*}{ Item } & \multicolumn{2}{|c|}{ Aryan energy } & \multicolumn{2}{|c|}{ Bhushan complex } & \multicolumn{2}{|c|}{ Kargali washery } \\
\hline & ROM & De-shaled coal & ROM & De-shaled coal & ROM & De-shaled coal \\
\hline Economic analysis (US \$/ton) & 4.76 & 6.65 & 1.70 & 3.51 & 1.05 & 5.36 \\
\hline Net value increment & & 2.39 & & 1.81 & & 4.31 \\
\hline Power plant efficiency analysis (\%) & 28.81 & 29.88 & 27.49 & 28.44 & 27.11 & 29.32 \\
\hline Net efficiency improvement & & 1.07 & & 0.96 & & 2.21 \\
\hline $\mathrm{lb}-\mathrm{CO}_{2} / \mathrm{kwh} \%$ & 2.30 & 2.27 & 2.34 & 2.32 & 2.35 & 2.29 \\
\hline lb- $\mathrm{CO}_{2} / \mathrm{kwh}$ percent-reduction & & 1.57 & & 1.24 & & 2.92 \\
\hline
\end{tabular}

Net value increment is calulated by substracting the (\$/ton) value obtained from the analysis for de-shaled and ROM coal for the respective test sites

Similarly, Net efficiency improvement is calulated by substracting the power plant efficiency percentage obtained from analysis for the de-shaled and ROM coal for the respective test sites

$\mathrm{lb}-\mathrm{CO}_{2} / \mathrm{kwh}$ percent-reduction is a percentage-wise calculation using the following method: (ROM-De-shaled)*100/ROM

for the coals like Kargali coal under specified economic parameters. Previous research showed an operating cost of a 500 tph unit approximately $0.5 \$ /$ ton ( $\$ 1.5$ million/year), and an initial capital cost $3200 \$ / \mathrm{tph}$, i.e., \$1.6 million/year (Honaker 2007). As such, the payback period would be less than a year. Furthermore, due to inherently dry process, additional saving can be expected due to the reduction in usage of process water. It should be noted that the economic analysis would be a coal operation specific and need a detail market study for the operation to identify actual profit. The sole purpose here for these analyses to demonstrate benefits of deshaling qualitatively.

Likewise, power plant efficiency analysis suggested an improvement of 1.07, 0.96, and 2.21 percentage-points for Aryan, Bhushan, and Kargali coal samples, respectively, relative to their ROM coal. In addition, the proposed deshaling system offers direct cost reductions to power plants, since the removal of rock at mine face reduces grinding demands, improves boiler efficiency, increases carbon burn-out, reduces slagging/fouling problems, decreases erosion rates and lowers bottom ash/fly ash loads. More importantly, the calculated improvement in profitability resulting from the enhanced fuel quality provides an important financial incentive for Indian companies to implement this clean coal technology for other important purposes such as environmental control. Other control measures for reducing downstream emissions of $\mathrm{CO}_{2}$, particulates and air toxics do not offer a similar financial return and require substantial capital investments that may be difficult to adopt given India's rapidly growing demands for energy infrastructure and other public services.

\subsection{Emission analysis}

For emission analyses, the specific energy generated (kwh/pound) from any given product can be estimated by using the net heat content of coal obtained from the feasibility studies (see Fig. 3 row ' $u$ '). Likewise, amount of $\mathrm{CO}_{2}$ generated per unit of coal can be estimated thermodynamically (row ' $v$ '). The carbon content of the coal (assuming $C=75 \%$ of dry mineral-matter free basis) and the elemental ratio of $\mathrm{CO}_{2}$ produced per unit of carbon (3.67), which is the theoretical limit used in the preliminary calculations. Based on these expressions, the amount of $\mathrm{CO}_{2}$ emitted per unit of useful heat generated was determined by dividing unit of $\mathrm{CO}_{2}$ emitted per unit of coal with specific useful energy generated (row ' $w$ '), followed by net emission reductions (row ' $x$ ').

Table 2 provides summary of net reductions in emissions per unit of specific energy for the best results obtained from the three test sites. From the analysis, percent reduction in $\mathrm{CO}_{2}$ emission can be achieved in the range of $1.2 \%-3.0 \%$ relative to the ROM coal, if deshaled coal from this technology is utilized for power generation. However, from a longer term perspective, the use of dry deshaling technologies to increase the availability of higher-quality coal feedstocks for downstream beneficiation process can serve as the first logical step in helping India to implement state-of-the-art clean coal technology processes to reduce total $\mathrm{CO}_{2}$ emissions.

\section{Conclusions}

The pilot-scale testing of the inclined deck dry coal separator demonstrated the superior capability for deshaling and rejecting undesirable mineral matters from the Indian coarse (i.e. $\geq 6 \mathrm{~mm}$ ) coal feedstocks currently utilized for thermal power generation. The testing was conducted at the three different coal preparation facilities in India, and showed successful recovery of the organic matter higher than $90 \%$ while rejecting significant amounts of incombustible high-ash rock (i.e., 1 ton of waste rock rejected per 4-5 tons of higher-value clean coal recovered). The 
feasibility analysis indicated that the technology can provide significant economic gains as well as can improve the overall power plant efficiency by $1 \%-3 \%$. Furthermore, emission rates of $\mathrm{CO}_{2}$ from the power plants can also be reduced $1 \%-3 \%$ by implementing this dry coal separation approach.

Acknowledgments Author expressed his gratitude to Eriez Manufacturing and Eriez India for the test equipment, field resources, and manpower that made much of this work possible. The author would like to acknowledge the tremendous support, field assistance and cooperation extended by the management and staff at Aryan Energy, Bhushan Steel \& Power, and Central Coal Ltd., Kargali Washery. Finally, author is very thankful for the guidance and enormous support provided by Dr. Gerald Luttrell (E. Morgan Massey Professor, Virginia Tech), Mr. Robert Bratton (Consultant, Bratton Engineering, LLC), Dr. Tathagata Ghosh (Assistant Professor, University of Alaska Fairbanks), and Dr. Rick Honaker (Professor and Chair, University of Kentucky).

Funding The author would like to acknowledge the financial support for this work provided by the United States Department of State under the Asia-Pacific Partnership of Clean Development and Climate. Project number S-L-MAQM-07-GR-341.

Open Access This article is distributed under the terms of the Creative Commons Attribution 4.0 International License (http://crea tivecommons.org/licenses/by/4.0/), which permits unrestricted use, distribution, and reproduction in any medium, provided you give appropriate credit to the original author(s) and the source, provide a link to the Creative Commons license, and indicate if changes were made.

\section{References}

Bhatt SM (2006) Effect of ash in coal on the performance of coal fired thermal power plants. Part I: primary energy Effects. Energy Sources 28(1):25-41

Biswal SK, Sahu AK, Parida A, Reddy PSR, Misra VN (2002) Prospects of dry beneficiation of Indian high ash non-coking coal: a review. J Mines Metals 51:53-57

Couch $\mathrm{G}$ (2002) Coal upgrading to reduce $\mathrm{CO}_{2}$ emissions. International Energy Agency, CCC/67, Paris, France, pp 1-72

Dwari RK, Rao HK (2007) Dry beneficiation of coal - a review. Miner Process Extr Metall Rev 28(3):177-234

Dwari RK, Rao HK (2008) Non-coking coal preparation by novel tirbo-electrostatic method. Fuel 87(17):3562-3571

Gouri CT, Chattopadhyay US, Kabiraj SK, Haldar DD (2007) Dry beneficiation of non-coking coal with the Allair Jig-a case study. In: Proceedings of Advanced Gravity Separation, National Metallurgical Laboratory, Jameshedpur, India, pp 167
Gupta N (2011) Dry deshaling of thermal coals in India. Master Thesis, Virginia Polytechnic Institute and State University

Gupta N, Bratton R, Luttrell G, Ghosh T, Honaker R (2012) Application of air-table technology for cleaning Indian coals. In: Young C, Luttrell G (eds) Separation technologies for minerals, coals, and earth resources. Society for Mining, Metallurgy \& Exploration, Englewood, CO, pp 199-210

Gupta N, Bratton R, Luttrell G, Ghosh T, Honaker R (2014) Upgrading Indian thermal coals using air-table dry deshaling. In: 31st International Pittsburgh Coal Conference, Oct. 2014, Pittsburgh, PA

Gupta N, Luttrell GH, Bratton RC (2016) Statistical optimization of dry deshaling for Indian coals using response surface methodology. Int J Coal Prep Util 36(3):125-138

Honaker RQ (2007) Coarse dry coal cleaning. Workshop on coal beneficiation and utilization of rejects: initiatives, policies and best practices, Ranchi, India, pp 22-24

Honaker RQ, Luttrell GH (2007) Development of an advanced deshaling technology to improve the energy efficiency of coal handling, processing, and utilization operations. University of Kentucky, Lexington

Honaker RQ, Luttrell GH, Lineberry GT (2006) Improved mining economics using near-face deshaling. Miner Metall Process 23 (2):73-79

Honaker RQ, Saracoglu M, Thompson E, Bratton R, Luttrell GH, Richardson V (2008) Upgrading coal using a pneumatic densitybased separator. Coal Prep Int J 28(1):51-67

IPCC (2013) The physical science basis, contribution of working group I to the fifth assessment report of the intergovernmental panel on climate change. Cambridge University Press, Cambridge

ISR (2005) Iron and steel review. 49(7), Hari Machines Limited, December 2005

MOC (2015) Ministry of Coal, Government of India. Accessed Sept 2015

MOP (2015) Ministry of Power, Government of India. Accessed Sept 2015

Sahu AK, Biswal SK, Parida A, Reddy PSR, Misra VN (2005) A study of dynamic stability of medium in air dense medium fluidised bed separator. India 56(1):103-107

Tiwari V, Wahr J, Swenson S (2009) Dwindling groundwater resources in northern India, from satellite gravity observations. Geophys Res Lett 36:L18401

Wills BA, Napier-Munn T (2006) Mineral processing technology, 7th edn. Elsevier, Amsterdam, p 65

World Bank (2015) Website accessed in September 2015 (comparative data for the year 2011)

Zamuda C, Sharpe M (2007) A case of enhanced use of clean coal in india: an essential step towards energy security and environmental protection. In: Workshop on Coal Beneficiation and Utilization of Rejects, pp 22-24

Zhao Y, Yang X, Luo Z, Duan C, Song S (2014) Progress in developments of dry coal beneficiation. Int J Coal Sci Technol 1 (1):103-112 